\title{
Diagnóstico quali-quantitativo da arborização urbana do Bairro Pantanal do município de Macapá-AP
}

\author{
Fabrício dos Santos LOBATO ${ }^{1 *}$, Alexandre Palheita MIRA루, Brenda Rebeca de Sousa BARBOSA ${ }^{1}$, \\ Alison Pereira de MAGALHÃES ${ }^{1}$, Rodrigo Teixeira de SOUZA ${ }^{1}$, Breno Marques da Silva e SILVA ${ }^{1}$
}

\author{
${ }^{1}$ Universidade do Estado do Amapá, Macapá, AP, Brasil. \\ *E-mail: faengflo@gmail.com \\ (Orcid: 0000-0002-8240-8039; 0000-0002-8659-6540; 0000-0003-3787-373X; 0000-0002-8058-256X; \\ 0000-0001-9051-8900; 0000-0003-0031-1450)
}

Recebido em 15/04/2020; Aceito em 03/02/2021; Publicado em 24/02/2021.

\begin{abstract}
RESUMO: Este trabalho teve como objetivo realizar um inventário quali-quantitativo da arborização urbana do bairro Pantanal, Macapá, AP. Portanto, foram avaliados as condições arbóreas através dos parâmetros: porte arbóreo das espécies identificadas, disposição do fuste, presença de fios elétricos sob as árvores e calçamento adequada, por meio de índices de diversidade de Shannom e Simpsom foram avaliados a riqueza de espécies, e foi delimitada a área das copas e a cobertura arbórea por rua. Foram identificados 144 indivíduos arbóreo, sendo 17 espécies, pertencentes a 9 famílias botânicas. As espécies Mangifera indica L. e Cocos nucifera L. totalizaram 59\% de indivíduos. A maioria dos indivíduos apresentam altura de até $5 \mathrm{~m}$. Foi observado que 67,36 $\%$ dos indivíduos apresentaram fuste reto. Quanto que 68,06\% estão com calçamento inadequado. Constatouse que $77,78 \%$ da população vegetal encontra-se livre de fiação elétrica. O índice de Shannon $(1,94)$ foi considerado baixo e o índice Simpson $(0,79)$ indicou alta dominância de uma única espécie. A arborização em relação as copas foram insuficientes para proporcionar conforto térmico e sombreamento adequado. Concluise que arborização do bairro Pantanal encontra-se no estado juvenil, a maioria da vegetação no bairro é de espécies exóticas, a maioria das árvores não apresentam problemas fisionômicos.
\end{abstract}

Palavras-chave: levantamento florístico; condições urbanas; dominância; frequência.

\section{Quali-quantitative diagnosis of urban arborization in the Pantanal Neighborhood of the municipality of Macapá, Amapá, Brazil}

\begin{abstract}
This study aimed to conduct a qualitative and quantitative inventory of urban afforestation in the Pantanal neighborhood, Macapá, AP. Therefore, the tree conditions were evaluated through the parameters: tree size of the identified species, stem arrangement, presence of electrical wires under the trees and adequate pavement, using Shannom and Simpsom diversity indexes, the species richness was evaluated, and the crown area and the tree cover per street were delimited. 144 tree species were identified, 17 species, belonging to 9 botanical families. The species Mangifera indica L. and Cocos nucifera L. totaled 59\% of individuals. Most individuals are up to $5 \mathrm{~m}$ tall. It was observed that $67.36 \%$ of the individuals had a straight shaft. As $68.06 \%$ are with inadequate paving. It was found that $77.78 \%$ of the plant population is free of electrical wiring. The Shannon index (1.94) was considered low and the Simpson index (0.79) indicated high dominance of a single species. The afforestation in relation to the crowns was insufficient to provide thermal comfort and adequate shading. It is concluded that the afforestation of the Pantanal neighborhood is in the juvenile state, most of the vegetation in the neighborhood is of exotic species, most of the trees do not present physiognomic problems.

Keywords: floristic survey; urban conditions; dominance; frequency.
\end{abstract}

\section{INTRODUÇÃO}

A arborização urbana é indispensável para que a população garanta uma boa qualidade de vida, contribuindo para o conforto, lazer, bem-estar. Além de fornecer sombra para pedestre e veículos, protege em parte contra a ação dos raios solares, amenizando altas temperaturas, reduz o impacto da chuva, ajuda a melhorar o valor estético e paisagístico de uma cidade (SHAMS, 2009; GONÇALVES, 2017; ROLLON; SIQUEIRA, 2018). Soma-se a esses benefícios, a redução da poluição atmosférica, e do impacto dos ventos (ROSSETTI et al., 2010).

O conjunto de vegetação nas cidades é que define o termo arborização urbana, sendo vegetação arbórea ou arbustiva, natural ou cultivada, distribuídas em vias públicas, porém, observa-se que a maioria das cidades brasileiras não possuem Plano Diretor, a falta desse planejamento prejudica o gerenciamento de diversos setores do desenvolvimento municipal, um deles é a arborização das vias públicas (LOPES et al., 2017). O mau planejamento pode acarretar problemas no desenvolvimento das árvores, espaço reduzido, solos compactados, entulhos, deficiência de água e nutrientes, podas severas, A escolha das espécies adequadas ao plantio é de fundamental importância, para evitar problemas (MARTINS, 2010; HERNÁNDEZ et al., 2017).

O crescimento urbano desordenado e aspectos negativos pela falta de planejamento, cresceram com desenvolvimento da industrialização, a vinda da população rural atrás de oportunidades no meio urbano ocasionou 
desequilíbrio na existência da sociedade com a natureza (SANTOS et al., 2018). Essa relação despertou o interesse de pesquisadores e gestores públicos em que se refere a circulação nos espaços, qualidade e preservação (RIBEIRO, 2009). E é necessário que haja um diagnóstico preciso, para isso, o estudo entre relação população e meio ambiente ganha destaque, pois está envolvida em seu cotidiano e os impactos são diretamente ligados aos mesmos. A percepção da população é extremamente importante para desenvolver soluções que mantêm e previnem problemas ambientais (RODRIGUES et al., 2010; SUFIA et a., 2019).

Esses estudos foram desenvolvidos em algumas cidades brasileiras como no caso de Manaus/AM (LINS NETO et al., 2016), Rorainópolis/RR (VELOSO, 2016), e Palmas/TO (MARINHO et. al., 2012), todos com o objetivo de mostrar a sociedade os benefícios ou malefícios de haver ou não um bom planejamento em relação a arborização urbana.

Para obter informações o inventário arbóreo e a maneira mais segura de avaliar as condições sobre quais árvores necessitam de tratamentos como; poda, remoção ou até mesmo lugares onde devem haver novos plantios, levando em conta o bom planejamento a fim de evitar transtornos nas vias públicas (LIMA NETO; BIONDI, 2014).

O geoprocessamento é uma grande ferramenta para avaliar as condições espaciais das cidades, a arborização urbana realizada por órgãos públicos vem ganhando auxilio pela utilização destes serviços, o gerenciamento urbano pelo Sistema de Informações Geográficas (SIG), gera importantes informações relacionadas ao meio urbano e seu uso (LIMA NETO, 2014).

Os SIG's passaram por uma grande evolução apartir de 1980, e suas principais melhorias foram na capacidade de processamento de dados, interface, execução por meio de modelos matemáticos e lógicos, aperfeiçoando o uso de informações espaciais (LONGLEY et al., 2013).
Lira; Cândido (2013) relatam o crescente avanço no desenvolvimento tecnológico, permitindo o uso dessas ferramentas em diversas áreas do conhecimento, como serviços públicos agronegócios e análises ambientais. A utilização das tecnologias acelera o processo de avaliação das condições ambientais e estruturais dos ambientes urbanos (PEREIRA et al., 2019).

Nesse contexto, o planejamento da arborização urbana combinado pelo uso de ferramentas que facilitam o diagnóstico torna-se necessário para promover tratamentos adequados e apontar decisões que possam corrigir ou indicar ações que elevem a qualidade do meio urbano. Deste modo, o presente estudo teve por objetivo realizar o levantamento da cobertura arbórea do Bairro Pantanal da cidade de Macapá-AP, a fim de identificar espécimes, avaliar os índices de diversidade de Simpson e Shannon presentes no bairro, e pelo método de georreferenciamento avaliar as reais condições de arborização no mesmo.

\section{MATERIAL E MÉTODOS}

\subsection{Caracterização da área de estudo}

O município de Macapá-AP de acordo com o IBGE (2010), possui uma área de aproximadamente $6.563,849 \mathrm{~km}^{2}$, população estimada em 503.327, localiza-se à margem esquerda do Rio Amazonas, coordenadas geográficas 00'02'84" latitude Norte e 51 03 '11' longitude Oeste de Greenwich. Clima tropical e subtropical, temperatura média anual de $27^{\circ} \mathrm{C}$, a pluviosidade média anual é de $2487 \mathrm{~mm}$ de acordo com a classificação de Köppen. Caracterizada por duas estações climáticas bem definidas: chuvosa (entre dezembro a julho); seca (entre agosto a novembro). Estudo concentrado nas vias públicas do bairro Pantanal localizado na zona norte do município de Macapá. (Figura 1).
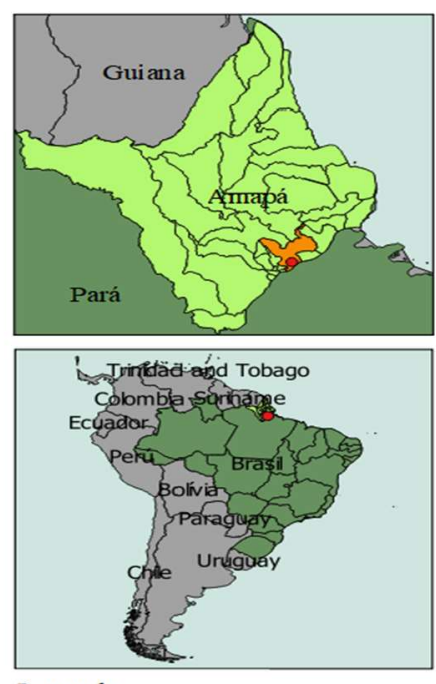

Legenda

- Área de estudo Limite de Macapá Limite do Amapá Limite do Brasil

Limite Continent

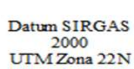
UTMZOona 22N Fonte de Dados
IBGE (2017)

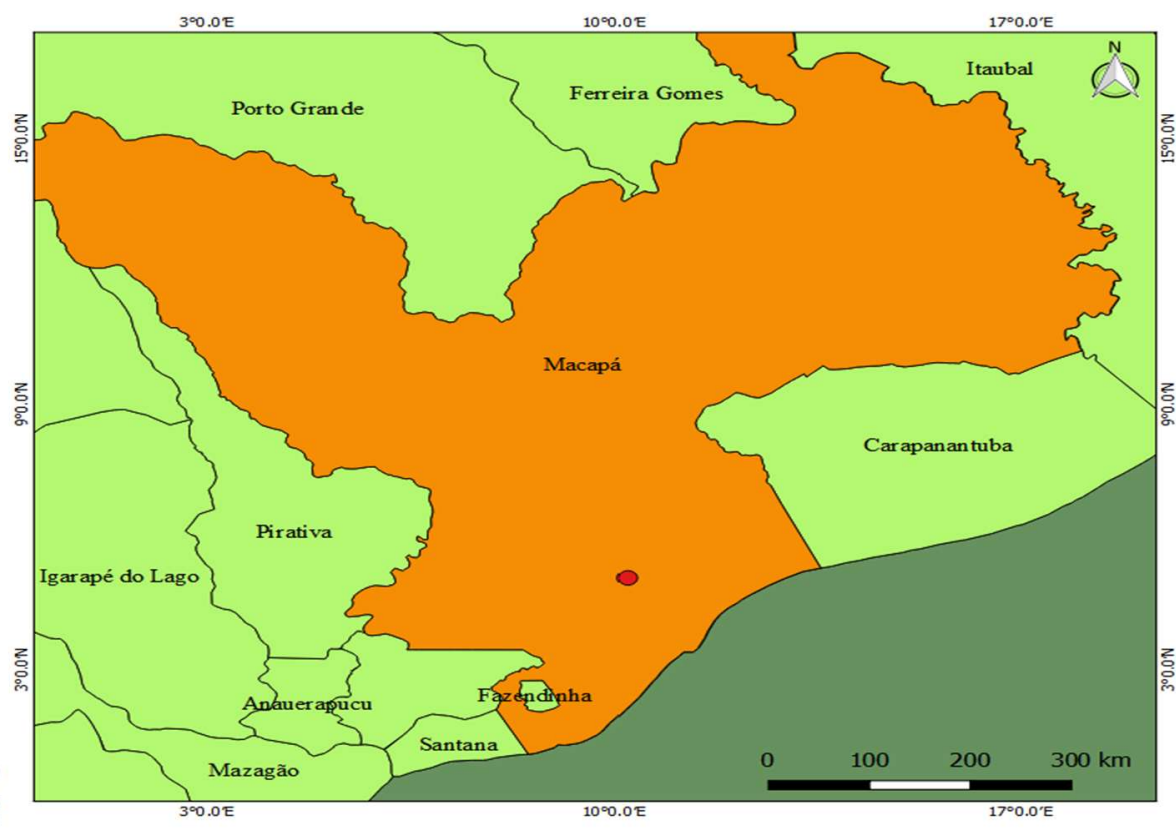

Figura 1. Localização geral da área de estudo.

Figure 1. General location of the study area.

\subsection{Coleta e análise de dados}

O bairro foi escolhido após pesquisas prévias sobre arborização urbana, visando áreas não inventariadas. A coleta dos dados foi realizada nos meses de setembro e outubro de 2019, observando indivíduos arbóreos e não arbóreos presentes nas calçadas. Para a realização do inventário, o 
método de levantamento de dados foi de caráter qualiquantitativo, do tipo censo. Para conhecimento dos componentes florísticos da arborização urbana foram utilizadas fichas de campo analisando aspectos como:

a) Características taxonômicas: a identificação ocorreu in loco através de características dendrológicas para a maioria das espécies, e as que não foram identificadas em campo houve a coleta de material botânico e elaboração de exsicatas para consultar ao herbário do Instituto de Pesquisas científicas e Tecnológicas do Estado do Amapá (HAMAB-IEAP) comparando com as amostras botânicas do herbário, em seguida a verificação dos nomes científicos e sinonímias atuais utilizando o site TROPICOS (MOBOT, 2020). E verificando o nome vulgar das espécies identificadas.

b) Características ecológicas: para determinar a origem fitogeográfica das espécies, considerando em nativas ou exóticas. Ocorreu por consulta ao banco de dados do site FLORA DO BRASIL (2020) e THE PLANT LIST (2020). Classificação das famílias segue as orientações do Angiosperm Phylogeny Group - APG IV (2016).

\section{Variáveis quantitativas:}

a) Porte arbóreo: foi verificado a altura estimada da árvore observando desde a base até a última folha do ápice da copa. A classificação em quanto ao porte, são elas: pequeno porte, espécies com até $5 \mathrm{~m}$ de altura; médio porte de 5 a $8 \mathrm{~m}$ de altura e de grande porte, superior a $8 \mathrm{~m}$, segundo o método de (ALMEIDA; BARBOSA, 2010).

Variáveis qualitativas:

a) Calçamento: foi analisado as condições de desenvolvimento das árvores em relação aos espaços adequados para o crescimento observando se o local onde a árvore está inserida apresenta alguma interferência (SIM/NÃO).

b) Fiação elétrica: foi observado a existência de rede elétrica sobre ou em conflito onde a árvore se encontra (SIM/NÃO).

c) Trânsito: foi observado a existência do passeio público, se as árvores estavam sujeitas à interação humana ou de veículos (SIM/NÃO).

d) Iluminação pública: foi observado a interferência das copas na iluminação de portes elétricos, verificando se apresentavam interferência na iluminação (SIM/NÃO).

e) Infestações de insetos: foi verificado através de análise visual, a ocorrência de pragas nos indivíduos arbóreos, como: plantas daninhas, cupins e formigas (SIM/NÃO).

f) Aspectos fisionômicos: foi verificado através de análise visual, sinais de danos mecânicos ou doenças nas árvores.

Para avaliar a diversidade de espécies da arborização do bairro pantanal, foi utilizado o índice de Shannon-Weaver. O uso do H' leva em consideração o número de espécies e equitabilidade dos mesmos (SANTOS, 2009). Uma das formulas de calcular o índice de diversidade e pela função de Shannon-Weaver, citado por Krippendorff (2009), dado por:

$$
\mathrm{H}^{\prime}=-\sum_{\mathrm{i}=1}^{\mathrm{s}} \text { pi. Ln pi }
$$

em que: $\mathrm{H}$ = índice de Shannon; $\mathrm{S}=$ número de espécies; e $\mathrm{Pi}=$ proporção da amostra contendo indivíduos de cada espécie i.
Para dominância (D) de espécie o índice de Simpson, este índice difere em relação ao peso de espécies raras e comuns, onde considera o mesmo peso para ambos (Melo, 2008), método citado por He; Hu (2005), dado por:

$$
1-\mathrm{D}=1-\sum \mathrm{p}_{\mathrm{i}}^{2}
$$

em que: $\mathrm{D}=$ dominância; $\mathrm{Pi}=$ valor total dos indivíduos de uma única espécie dividido pelo valor total de indivíduos da área amostrada.

Para o georreferenciamento das árvores a marcação dos pontos, foram tiradas a partir da base de cada indivíduo arbóreo, utilizando o aplicativo UTM Geo Map (desenvolvido pela Y2 tech disponível na Play Store), salvando as coordenadas em planilhas do EXCEL ${ }^{\circledR}$, em seguida descarregando no Software QGIS 2.18, que oferece diversas possibilidades de criação, edição, importação, exportação e análises de metadados.

Para delimitação das áreas da copa, foi empregado o método semelhante ao estudo de Biondi e Lima Neto (2011), onde após o georreferenciamento, foi utilizado Software Google Earth Pro com imagens de 2019, por meio de vetores do tipo polígono, foram observados somente árvores superiores a $2 \mathrm{~m}$ de altura e calculadas em $\left(\mathrm{m}^{2}\right)$, no Software QGIS 2.18 e as larguras das vias foram medidas em campo. Para o calcular do Índice de Cobertura Arbórea (ICA) de cada rua foi feito o somatório das áreas das copas em $\left(\mathrm{m}^{2}\right)$, dividido pelo total da via $\left(\mathrm{m}^{2}\right)$ multiplicado por cem, conforme a equação:

$$
\mathrm{ICA}=\frac{\sum \text { Área da copa }\left(\mathrm{m}^{2}\right)}{\text { Área total das vias }\left(\mathrm{m}^{2}\right)} \times 100
$$

\section{RESULTADOS}

Nas 17 vias inventariadas do bairro Pantanal foram encontrados 144 indivíduos arbóreos, distribuídos em 17 espécies, 15 gêneros e 9 famílias botânicas. As famílias mais ricas em espécies foram: Myrtaceae quatro espécies, Fabaceae três espécies, Anacardiaceae, Arecaceae e Chrysobalanaceae, com duas espécies cada. Apocynaceae, Combretaceae, Meliaceae e Moraceae, com uma espécie cada. As espécies com maiores frequências foram: Mangifera indica L. com a frequência de 31,94\% (Anacardiaceae), Cocos nucifera L. com $27,08 \%$ (Arecaceae) e Veitchia merrilli com 15,97\% (Arecaceae), que juntas representam $(74,99 \%)$ do inventário. Os $(25,01 \%)$ restantes da arborização estão distribuídos em outras 14 espécies (Tabela 1).

No bairro Pantanal, ocorreu a incidência de espécies superiores a valores recomendados para a arborização, a mangueira (Mangifera indica L.), coqueiro (Cocos nucifera L.) e palmeira (Veitchia merrilli) apresentam um número superior do limite de $15 \%$, como demostra a Tabela 1 . A origem das espécies encontradas no bairro, foi observado uma maior ocorrência de espécies exóticas com 58\% e nativas $42 \%$ dos indivíduos. A espécie nativa de maior representatividade foi Licania tomentosa (oiti) por 10 indivíduos (6,9\%). Enquanto, que os destaques das espécies exóticas foram Mangifera indica (mangueira) com 46 indivíduos (31,9\%) e Cocos nucifera (coqueiro) com 39 indivíduos (27,1\%). 
Tabela 1. Espécies da arborização urbana do bairro Pantanal, Macapá, AP, Brasil.

Table 1. Species of urban afforestation in the Pantanal neighborhood, Macapá, AP, Brazil.

\begin{tabular}{|c|c|c|c|c|c|}
\hline Família & Nome Científico & Nome Vulgar & Origem & NI & Fr. $(\%)$ \\
\hline \multirow{2}{*}{ Anacardiaceae } & Anacardium occidentale $\mathrm{L}$. & Cajueiro & Nativa & 2 & 1,4 \\
\hline & Mangifera indica $\mathrm{L}$. & Mangueira & Exótica & 46 & 31,9 \\
\hline Apocynaceae & Plumeria pudica Jacq. & Jasmim do Caribe & Exótica & 2 & 1,4 \\
\hline \multirow{2}{*}{ Arecaceae } & Cocos nucifera L. & Coqueiro & Exótica & 39 & 27,1 \\
\hline & Veitchia merrillii (Becc.) HE Moore & Palmeira & Exótica & 23 & 16 \\
\hline \multirow{2}{*}{ Chrysobalanaceae } & Chrysobalanus icaco L. & Ajuru & Nativa & 1 & 0,7 \\
\hline & Licania tomentosa (Benth.) Fritsch & Oiti & Nativa & 10 & 6,9 \\
\hline Combretaceae & Terminalia catappa $\mathrm{L}$. & Castanholeira & Exótica & 5 & 3,5 \\
\hline \multirow{3}{*}{ Fabaceae } & Andira inermis (W. Wright) Kunth ex DC. & Alvineira & Nativa & 1 & 0,7 \\
\hline & Caesalpinia ferrea Mart. ex Tul. & Pau-Ferro & Nativa & 1 & 0,7 \\
\hline & Caesalpinia pluviosa DC. & Sibipiruna & Nativa & 1 & 0,7 \\
\hline Meliaceae & Azadirachta indica A. Juss. & Nim & Exótica & 2 & 1,4 \\
\hline Moraceae & Ficus benjamina $\mathrm{L}$. & Figueira & Exótica & 3 & 2,1 \\
\hline \multirow{4}{*}{ Myrtaceae } & Eucalyptus urograndis & Eucalipto & Exótica & 1 & 0,7 \\
\hline & Psidium guajava L. & Goiabeira & Nativa & 2 & 1,4 \\
\hline & Sysygium cumini L. Skeels & Jambolão & Exótica & 3 & 2,1 \\
\hline & Sysygium malaccense (L.) Merr. \& LM Perry & Jambeiro & Exótica & 2 & 1,4 \\
\hline
\end{tabular}

Nota: $\mathrm{NI}=$ Número de indivíduos; Fr. $(\%)=$ Frequência.

A classificação em relação ao porte dos indivíduos arbóreos levantados, 39,58\% do total de indivíduos apresentaram altura de pequeno porte, inferior a $5 \mathrm{~m}$. sendo a maior frequência entre os indivíduos. Seguindo pela a altura classificada como médio porte de 5 a $8 \mathrm{~m}$, com $32,63 \%$ dos indivíduos. Apenas $27,79 \%$ são árvores de grande porte com altura superior a $8 \mathrm{~m}$. Mostrando que a maioria das árvores do bairro e de pequeno porte e tem reflexo direto nas condições urbanas (Figura 2).

$\mathrm{Na}$ interferência da iluminação pública dos postes elétricos, 58,33\% dos indivíduos necessitam de tratos como a poda e distanciamento apropriado e 41,66\% não obstruí a iluminação. Observou-se que grande parte das espécies $(68,06 \%)$ não se encontram com calçamento adequado para desenvolvimento das árvores, as escolhas inadequadas de espécies podem causar danos nas vias, dificultando a locomoção de pedestre como Ficus benjamina que apresenta um sistema radicular superficial.

Quanto à disposição de fiação elétrica sob árvores, verificou-se que poucos indivíduos $(22,22 \%)$ estão condicionados a presença fios, e grande maioria $(77,78 \%)$ encontra-se livre da fiação. No que se refere a existência de trânsito de pessoas e veículos $90,02 \%$ possui essa movimentação, entretanto, a existência do trânsito não interfere no desenvolvimento (Figura 3).

Avaliação nos aspectos fisionômicos dos indivíduos arbóreos, verificando-se que $86,80 \%$ das amostras não apresentam nenhum tipo de dano no fuste sendo que, somente 13,19\% apresentam algum tipo de injúria. Já em relação as condições da copa, 95,13\% dos indivíduos apresentam normalidade e 4,86\% mostram algum tipo de dano. A morfologia do fuste, foi encontrado $67,36 \%$ dos indivíduos com o fuste reto, seguindo do formato \pm inclinado $26,38 \%$ e a minoria $6,25 \%$ apresentam o formato inclinado (Figura 4).

A incidência de plantas daninhas, $90 \%$ das árvores não apresentaram ocorrência e foi encontrado em apenas $10 \%$, no caso de cupins o indicativo da presença dessa espécie foi baixo 13,88\%. Porém, a presença de formiga foi alta $81,94 \%$ (Figura 5).

Ao que se refere ao índice de diversidade de Shannon $\left(\mathrm{H}^{\prime}\right)$, aplicado no Bairro Pantanal, foi possível obter o valor de 1,94. Já no cálculo de dominância das espécies estipulado por Simpson, o valor obtido resultou em 0,79 . O mapa produzido na (Figura 6) é possível verificar a distribuição espacial dos 144 indivíduos presentes nas vias públicas do Pantanal, observa-se que as espécies mais frequentes Mangifera indica L. encontra-se amplamente dividida no bairro e Cocos nucifera L. estão reunidas em um determinado ponto.

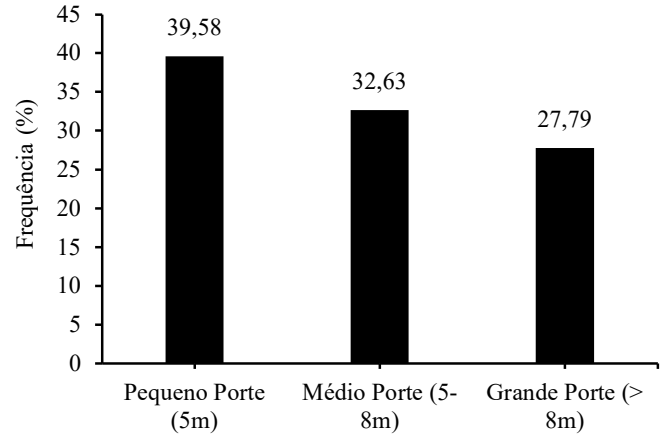

Figura 2. Distribuição dos indivíduos arbóreos quanto ao porte na arborização do bairro Pantanal, Macapá, AP, Brasil.

Figure 2. Distribution of arboreal individuals as to size in afforestation in the Pantanal neighborhood, Macapá, AP, Brazil.

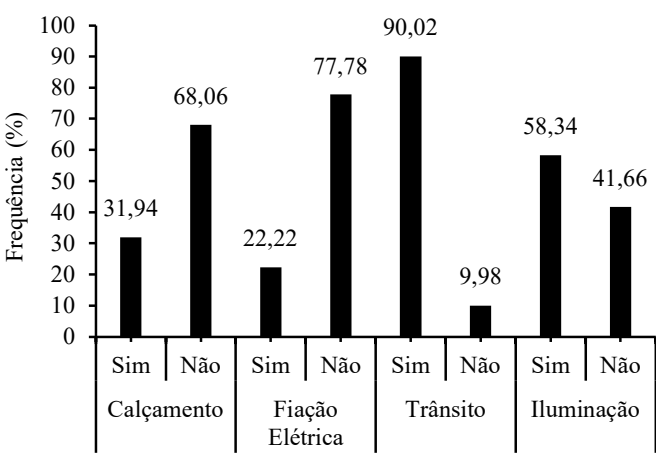

Figura 3. Estruturas públicas em conflitos com a arborização urbana no bairro Pantanal, Macapá, AP, Brasil.

Figure 3. Public structures in conflict with urban afforestation in the Pantanal neighborhood, Macapá, AP, Brazil. 


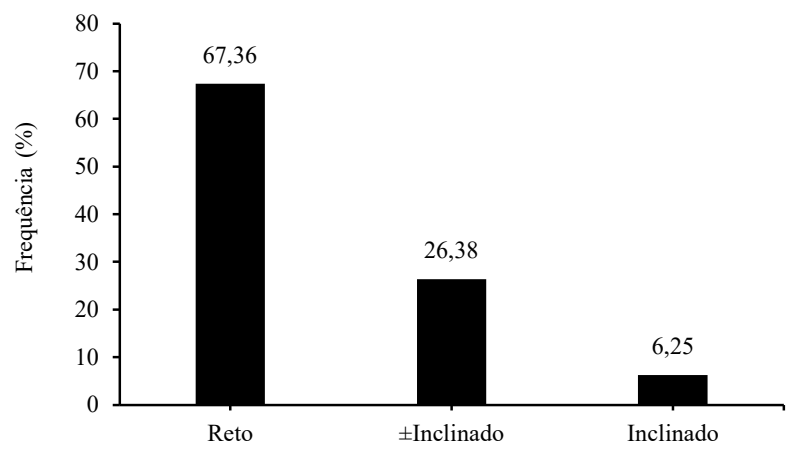

Figura 4. Aspectos do fuste das árvores no bairro Pantanal, Macapá, AP, Brasil.

Figure 4. Aspects of the tree trunk in the Pantanal neighborhood, Macapá, AP, Brazil.

Das 17 vias do bairro pantanal três ruas não apresentam nenhum indivíduo arbóreo, o índice de cobertura arbórea foi realizado somente em 14 vias do bairro (Figura 7). A área total das ruas inventariadas corresponde a $62.823,00 \mathrm{~m}^{2}$. Equivale a $23,15 \%$ da área total do bairro que é de $271.360,36 \mathrm{~m}^{2}$.

A via que apresentou o melhor Índice de Cobertura Arbórea foi a avenida Cecília Vicente da Paixão com $10,30 \%$ da via coberta, contendo 4 indivíduos arbóreos. A segunda via foi a rua Beira Mar possuindo 30 indivíduos arbóreos, 10,24\% de cobertura das copas. Considerando a quantidade de árvores das vias, a que possuir maior quantidade deveria apresentar maior índice. Entretanto, a extensão da rua Beira Mar $\left(9.612,00 \mathrm{~m}^{2}\right)$ é superior a avenida Cecília Vicente da Paixão $\left(2.861,00 \mathrm{~m}^{2}\right)$, logo, a área da copa foi menor em relação a primeira via. Seguindo pela rua Euci Rodrigues Farias $\left(7.046,00 \mathrm{~m}^{2}\right)$ possuindo 20 indivíduos arbóreo, apresentou $8,97 \%$ e avenida Mario Nunes $\left(3.002,00 \mathrm{~m}^{2}\right)$ tendo 7 indivíduos com o índice arbóreo de 8,80\%. Essas vias foram as mais expressivas na cobertura arbórea do bairro Pantanal (Tabela 2).

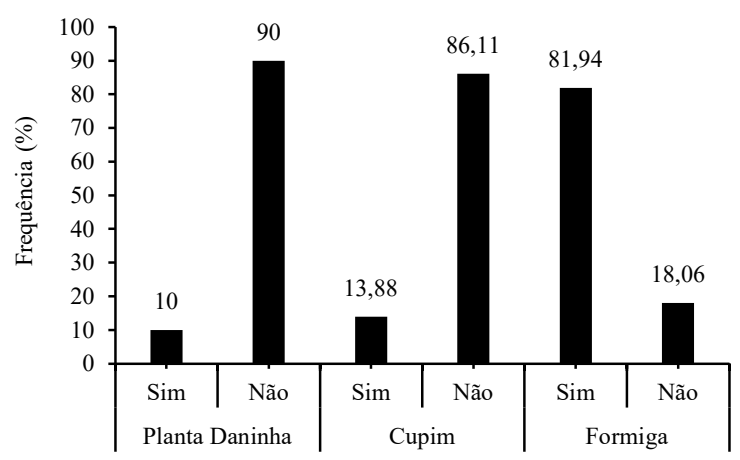

Figura 5. Infestações de pragas nas árvores do bairro Pantanal, Macapá, AP, Brasil.

Figure 5. Pest infestations in trees of the Pantanal neighborhood, Macapá, AP, Brazil.
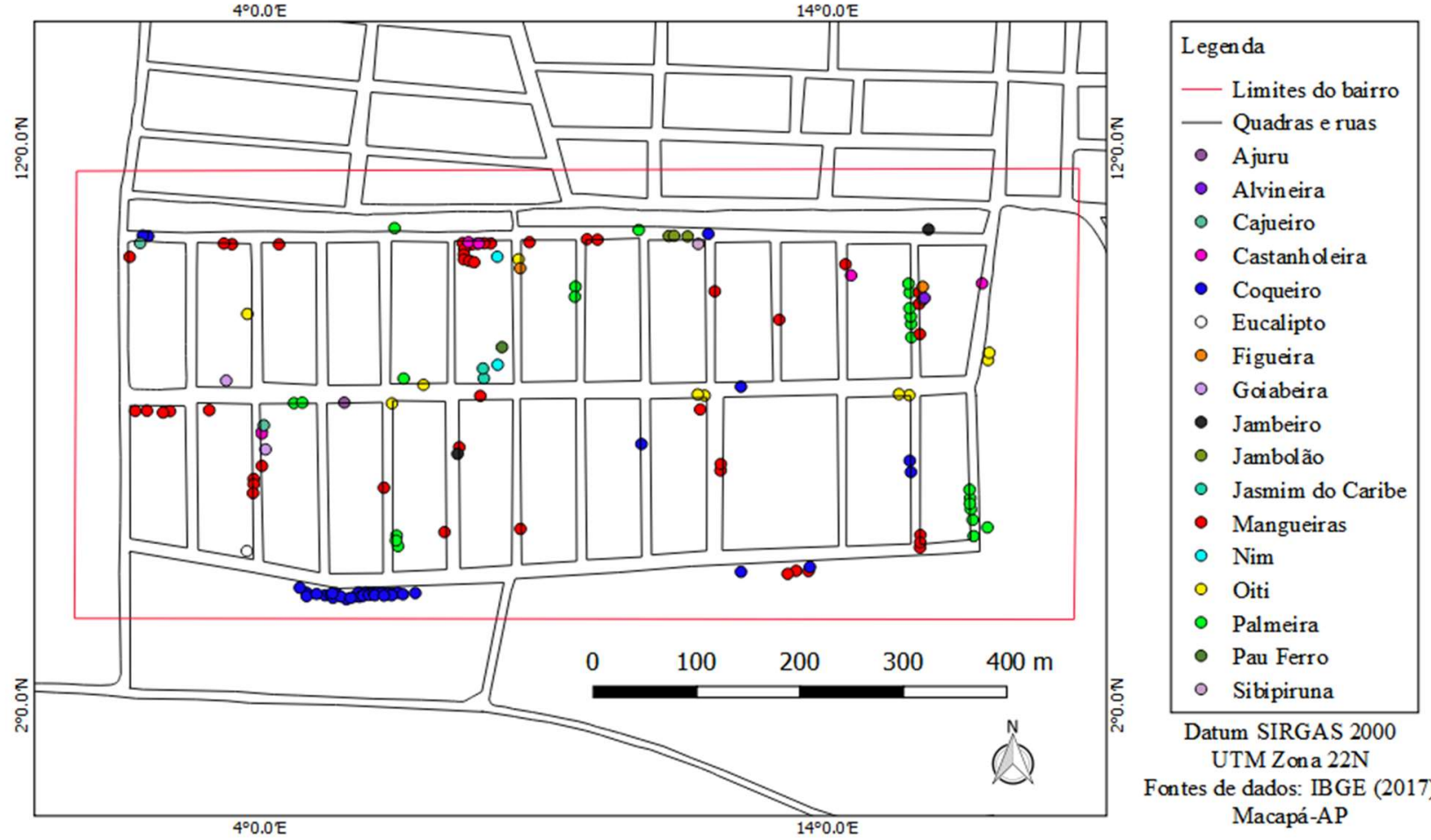

Figura 6. Distribuição espacial das espécies presentes no bairro Pantanal, Macapá, AP, Brasil.

Figure 6. Spatial distribuition of species present in the Pantanal neighborhood, Macapá, AP, Brazil. 


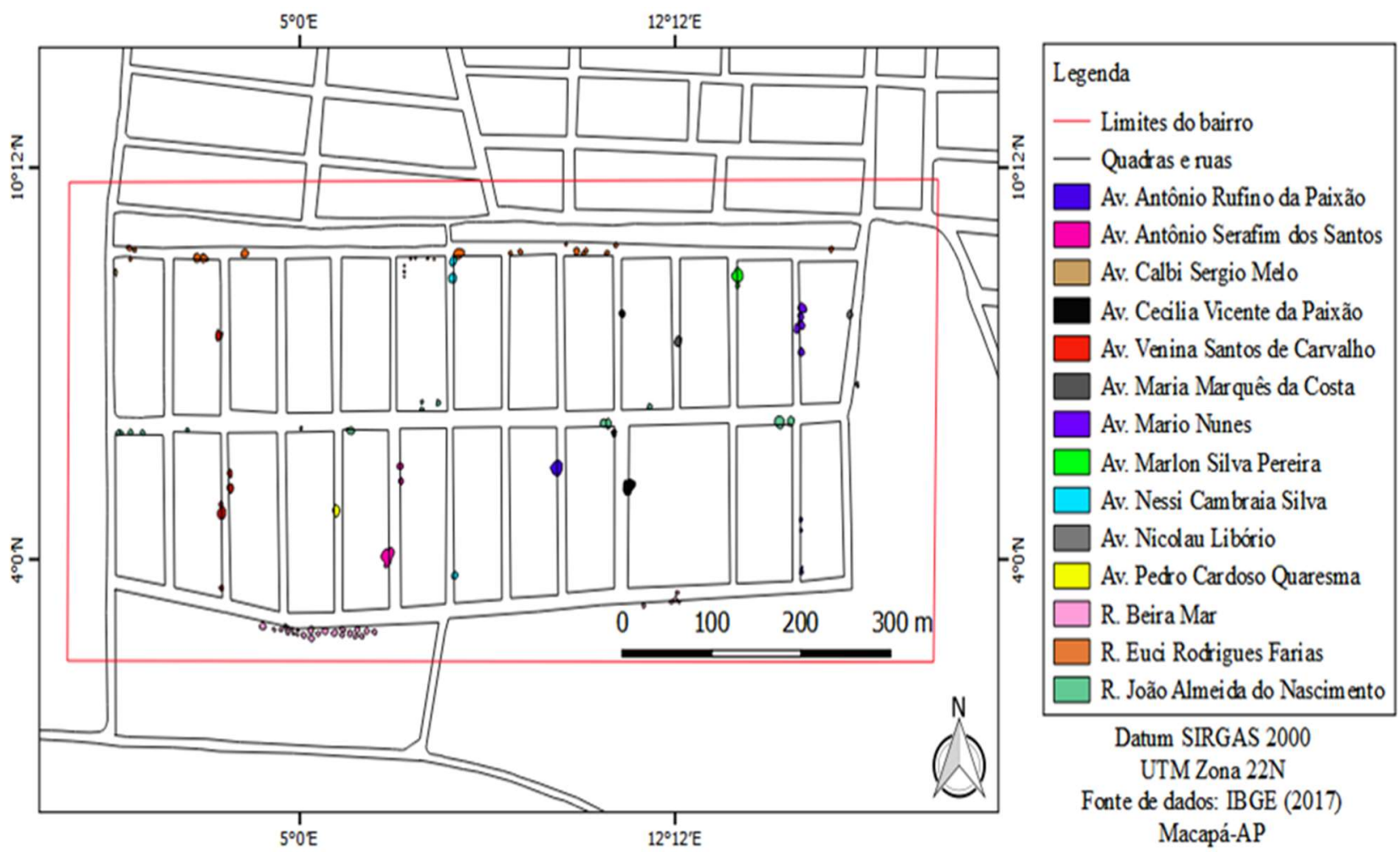

Figura 7. Cobertura arbórea das ruas do bairro Pantanal, Macapá, AP, Brasil.

Figure 7. Tree cover of the streets of the Pantanal neighborhood, Macapá, AP, Brazil.

Tabela 2. Áreas das ruas e áreas de projeção das copas do bairro Pantanal, Macapá, AP, Brazil.

Table 2. Streets areas and canopy projection areas in the Pantanal neighborhood, Macapá, AP, Brazil.

\begin{tabular}{lcccc}
\hline Vias & Área da Via $\left(\mathrm{m}^{2}\right)$ & Projeção da copa $\left(\mathrm{m}^{2}\right)$ & NI & Sombreamento por rua \\
\hline Av. Calbi Sergio Melo & $3.071,00$ & 19,3 & 1 & $0,60 \%$ \\
Av. Venina Santos de Carvalho & $3.324,00$ & 240 & 8 & $7,20 \%$ \\
Av. Pedro Cardoso Quaresma & $3.361,00$ & 120 & 1 & $3,50 \%$ \\
Av. Antônio Serafim dos Santos & $3.491,00$ & 108,97 & 6 & $3,10 \%$ \\
Av. Nessi Cambraia Silva & $3.141,00$ & 148,47 & 3 & $4,72 \%$ \\
Av. Antônio Rufino da Paixão & $2.993,00$ & 85,08 & 1 & $2,84 \%$ \\
Av. Cecília Vicente da Paixão & $2.861,00$ & 295,27 & $40,30 \%$ \\
Av. Maria Marquês da Costa & $1.639,00$ & 51,55 & 1 & $3,10 \%$ \\
Av. Marlon Silva Pereira & $3.279,00$ & 178,61 & 2 & $5,40 \%$ \\
Av. Mario Nunes & $3.002,00$ & 266,8 & 7 & $8,80 \%$ \\
Av. Nicolau Libório & $2.879,00$ & 173,57 & 3 & $6,02 \%$ \\
R. Euci Rodrigues Farias & $7.046,00$ & 632,71 & 20 & $8,97 \%$ \\
R. João Almeida do Nascimento & $13.124,00$ & 413,82 & 15 & $3,15 \%$ \\
R. Beira Mar & $9.612,00$ & 984,65 & 30 & $10,24 \%$ \\
\hline Total & $62.823,00$ & $3.718,80$ & 102 & \\
\hline
\end{tabular}

Nota: NI = Número de indivíduos.

\section{DISCUSSÃO}

A maioria de indivíduos presentes na arborização frequentemente é representado por poucas espécies, como observado nos estudos de (ARAÚJO et al., 2009; RODOLFO JUNIOR et al., 2008). O bairro Pantanal está na média considerando a distribuição de espécie, para que esteja classificado como boa, deve-se apresentar de 10 a 20 tipos diferentes de espécie (MILANO; DALCIN, 2000). Havendo uma baixa diversidade de espécies pode acarretar em implicações para a biodiversidade do ecossistema no meio urbano, ocorre uma interferência no equilíbrio biológico, tendo em vista que uma vegetação diversificada e de suma importância para uma boa estrutura de comunidade biológica (CADORIN et al., 2008). Entretanto, a frequência não se deve ultrapassar a 15\% para uma única espécie na arborização urbana, para garantir que as árvores obtenham condições fitossanitárias, número superior a 15\% há grandes chances de colocar em risco vários indivíduos arbóreos (REDIN et al. 2010). No o bairro Pantanal, ocorreu a incidência de espécies superiores a este valor recomendado (Tabela 1).

De acordo com Barbosa (2015) espécies nativas deveriam ter mais representatividade na arborização urbana por auxiliarem na manutenção e recuperação de uma paisagem. Bobrowisk (2015) atenta quanto a superioridade de espécies exóticas no meio urbano, recomenda que sejam removidas ou substituídas, afim de evitar problemas como alteração da paisagem natural e perda da biodiversidade. Algumas espécies exóticas não afetam na vegetação local, e que preferencialmente estas espécies não apresentem alta capacidade de dispersão nos locais onde estão inseridas 
(MEIRA, 2015).

Grande parte dos indivíduos arbóreos do bairro Pantanal não ultrapassam os $8 \mathrm{~m}$ de altura (Figura 2), levando-se em conta a recente criação deste bairro Portilho (2006) relata que o município de Macapá durante a década de 1990, sofreu o enquadramento de diversos lotes, principalmente na região norte da cidade. Fundamentado no documento "Histórico de Loteamento Urbano" do IMAP (s.d.) que descreve o surgimento bairros como: Brasil novo (1990), Infraero (1997), Renascer (1998) e o entre eles o Pantanal (1998), o que explica a baixa interferência nos fios elétricos e a predominância de indivíduos de pequeno e médio porte considerados ainda jovens.

Biondi e Lima Neto (2011) afirma que os problemas futuros da arborização se devem as condições de tratos inicias nas mudas. Este resultado para interferência das copas na fiação elétrica como visto na Figura 3 mostra-se superior ao valor encontrado no estudo de Ferro (2015) realizado em Parauapebas, Pará, onde $8,48 \%$ das copas das árvores não entravam em conflito com a rede elétrica devido à manutenção constante das copas, com podas frequentes. $\mathrm{O}$ planejamento de arborização nem sempre é incluído no planejamento urbano, que pode propiciar iniciativas desprovidas de conhecimento, como o plantio de espécies inadequadas no local, por consequência o surgimento de problemas para o setor elétrico (ALMEIDA E BARBOSA, 2010).

De acordo com Pivetta e Silva Filho (2002) os fustes de árvores urbanas devem apresentar lenho resistente. Portanto, em relação as condições do fuste as amostras encontram-se saudáveis e uma pequena parcela carece de reparos. A tortuosidade pode estar associada ao desenvolvimento dos indivíduos, no seu manejo até a forma adulta e largura das calçadas onde estão inseridas, modificando vias e interferindo a movimentação de veículos e pedestres (BIONDI e LIMA NETO, LIMA NETO, 2014).

Os insetos podem ser considerados pragas, entretanto, muitos estabeleceram relação mutualística e nos indivíduos que tinham a população desses insetos não foi observado nem um indicativo de dano. As formigas ajudam na dispersão de sementes e frutos, também protegem as árvores contraataques de outros insetos (DAVIDSON et al., 1991).

O valor de Shannon $\left(\mathrm{H}^{\top}\right)$ apresentado é considerado baixo quando comparado com os índices de arborização de outros estudos em cidades brasileiras, como no caso do Rio de janeiro/RJ (NASCIMENTO et al., 2014), Gurupi/TO (SANTOS et al., 2013), Ribeirão Preto/SP (ROMANI et al., 2012) e Rio Branco/AC (MARANHO e PAULA, 2013), respectivamente os valores de diversidade de Shannon foram $2,26,2,37,3,14$, e 3,95. Comunidades que apresentam riqueza elevada ou valores semelhantes, os índices podem variar de 2,4 a 4,3, e para comunidades arbóreas com menores riquezas ou com alta dominância de alguma espécie os valores de 1,26 a 1,39 (MOTA et al., 2013), valores inferiores em relação ao encontrado nesse estudo $(1,94)$.

Em relação ao índice de dominância de Simpson, o levantamento resultou no valor de 0,79 , inferior ao resultado encontrado no estudo de praças do centro de Gurupi/TO no valor de 0,81 (SANTOS et al., 2013), e superior no levantamento da praça 4 do município de Guarapuava/PR no valor de 0,31 (KRAMER e KRUPEK, 2012). O índice de Simpson demonstra a possibilidade de dois indivíduos relacionados ao acaso, serem da mesma espécie, o índice varia de 0 a $1, \operatorname{logo}$, quando o valor for mais próximo a 1 , terá maior dominância de determinada espécies (URAMOTO et al, 2005).

As ruas do bairro Pantanal apresentaram valores muito inferiores ao que é recomendado em sombreamento urbano (Tabela 2). A proteção das copas em áreas urbanas deve apresentar no mínimo 30\% de ICA para fornecer conforto térmico à população (LOMBARDO, 1985). O mesmo autor salienta que valores abaixo de $5 \%$ as características climáticas se igualam a regiões desérticas, que foi o caso das ruas Calbi Sergio Melo, Pedro Cardoso Quaresma, Antônio Serafim dos Santos, Nessi Cambraia Silva, Antônio Rufino da Paixão, Maria Marquês da Costa e João Almeida do Nascimento que apresentaram $0,60 \%, 3,50 \%, 3,01 \%, 4,72 \%, 2,84 \%, 3,10 \%$ e $3,15 \%$ de cobertura arbórea, respectivamente. Partindo destas hipóteses, autores como Melo e Romani (2008) e Arruda (2013) enfatizam a ideia de que órgãos públicos elaborem planos adequados de arborização visualizando características como: cores vivas para uma visibilidade e estética, fornece sombra para um bom conforto térmico, proteção e alimentação para a fauna, de modo que propicie uma relação harmônica entre usuário e meio ambiente.

Gonçalves (2017), realizou uma avaliação da cobertura arbórea das ruas do município de Itacoatiara - AM, num total de 9 ruas apenas uma via mostrou valor de ICA recomendado para arborização atingindo o percentual de 34\%, os valores restantes foram semelhantes ao encontrado neste estudo, onde nenhuma rua alcançou o valor recomendado. Conforme Carcereri (2016) o uso das informações fornecidas pelo Índice de Cobertura Arbórea para avaliar o espaço ocupado pela árvore e a interação delas no meio ambiente, bem como, o planejamento futuro torna-se bem mais fácil.

\section{CONCLUSÕES}

A partir dos resultados, constatou-se a predominância das espécies Mangifera indica (31,94\%) e Cocos nucifera L. (27,10\%). Verificou-se uma alta dominância de espécies arbóreas pelo índice de Simpson e uma baixa diversidade de espécie pelo índice de Shannon. Assim, recomenda-se procedimentos de introdução de novas espécies com a finalidade de diminuir a frequência destas duas espécies e também enfraquecer o domínio de espécies exóticas, afim de contribuir com a visibilidade estética, proteção e conforto térmico.

A arborização do bairro Pantanal ainda está no estado juvenil, considerando que boa parte de seus indivíduos arbóreos estão classificados como pequeno e médio porte. Tendo influência direta no Índice de Cobertura Arbórea, a quantidade de árvores é insuficiente para propiciar o conforto térmico para a população presente no bairro Pantanal.

A avaliação tangendo as condições encontradas mostrou que o município não realizou um planejamento adequado para a arborização, tendo em vista que a maioria das árvores no bairro Pantanal não apresentaram boas condições de plantio relacionados as calçadas, que são um dos grandes empecilhos para um bom desenvolvimento.

\section{REFERÊNCIAS}

ANGIOSPERM PHYLOGENY GROUP (APG IV). An update of the Angiosperm Phylogeny Group classification for the orders and families of flowering plants: APG IV. Botanical Journal of the Linnean Society, v. 181, p. 1-20, 2016. DOI: https://doi.org/10.1111/boj.12385

ALMEIDA, J. R.; BARBOSA, C. G. Diagnóstico da 
arborização urbana da cidade de Cacoal-RO. Revista da Sociedade Brasileira de Arborização Urbana, Piracicaba, v. 5, n. 1, p. 61-81, 2010. DOI: http://dx.doi.org/10.5380/revsbau.v5i1.66239

ARAÚJO, A. C.; RIBEIRO, I. A. M.; MORAIS, M. S.; ARAÚJO, J. L. O. Análise quali-quantitativa da arborização no bairro presidente Médici, Campina Grande-PB. Revista da Sociedade Brasileira de Arborização Urbana, v. 4, n. 1, p. 133-144, 2009. DOI: http://dx.doi.org/10.5380/revsbau.v4i1.66261

ARRUDA, L. E. V. Índice de área verde e de cobertura vegetal no perímetro urbano central do município de Mossoró-RN. Revista Verde de Agroecologia e Desenvolvimento Sustentável, Mossoró, v. 8, n. 2, p. 13-17, 2013.

BARBOSA, R. P.; PORTELA, M. G. T.; MACHADO, R. R. B.; SÁ, A. S. Arborização da Avenida Deputado Ulisses Guimarães, Bairro Promorar, zona sul de Teresina - PI. Revista da Sociedade Brasileira de Arborização Urbana, Piracicaba, v. 10, n. 2, p. 78-89, 2015. DOI: http://dx.doi.org/10.5380/revsbau.v10i2.63132

BIONDI, D.; LIMA NETO, E. M. Pesquisa em Arborização de Ruas. Curitiba: FUPEF, 2011. 150p.

BOBROWSKI, R. Influencia das espécies exóticas invasoras na expressão da diversidade da arborização de ruas de Curitiba-PR. Revistada Sociedade Brasileira de Arborização Urbana, Piracicaba, v. 10, n. 2, p. 27-39, 2015. http://dx.doi.org/10.5380/revsbau.v10i2.63242

CADORIN, D. A.; SILVA, L. M.; HASSE, I.; BETT, C. F.; EMER, A.; OLIVEIRA, J. R. Características da arborização dos bairros Cadorin, Parzianello e La Salle em Pato Branco-PR. Revista da Sociedade Brasileira de Arborização Urbana, Piracicaba, v. 3, n. 4, p. 40-52, 2008. http://dx.doi.org/10.5380/revsbau.v3i4.66371

CARCERERI, V. H. Análise da cobertura arbórea das praças de Curitiba - PR. Revista da Sociedade Brasileira de Arborização Urbana, Piracicaba, v. 11, n. 2, p. 12-26, 2016. http://dx.doi.org/10.5380/revsbau.v11i2.63411

DAVIDSON, D. W.; FOSTER, R. B.; SNELLING, R. R.; LOZADA, P. W. Variable Composition of Some Tropical Ant-Plant Symbioses. In: LEWINSOHN, T.; PRICE, P.; BENSON, W. W.; FERNANDES, G. W. (Eds.). Plant-Animal interactions: evolutionary in tropical and temperate regions. John Wiley \& Sons, Inc., 1991. pp. 145-162.

FERRO. C. C. S. Inventário quali-quantitativo da arborização viária de um trecho da Rodovia PA - 275 no município de Parauapebas - PA. Revista da Sociedade Brasileira de Arborização Urbana, Piracicaba, v. 10, n. 3, p. 73-84, 2015. http://dx.doi.org/10.5380/revsbau.v10i3.63071

FLORA DO BRASIL 2020 EM CONSTRUÇÃO. Jardim Botânico do Rio de Janeiro. Disponível em: $<$ http://reflora.jbrj.gov.br/>. Acesso em: $12 \mathrm{mar} / 2020$.

GONÇALVES, W. B.; CORAL, D. J.; SIQUEIRA, M. V. B. M. Caracterização da arborização urbana no bairro centro do município de Ibitinga/SP. Revista da Sociedade Brasileira de Arborização Urbana, Piracicaba, v. 12, n. 3, p. 66-79, $2017 . \quad$ DOI: http://dx.doi.org/10.5380/revsbau.v12i3.63537

HERNÁNDEZ, S.; HERNÁNDEZ, J. A.; ALCARAZ, B. Planning and Designing Low - Carbon Cities in Mexico. Cuadernos de Vivienda y Urbanismo, v. 11, n. 22, 2018. DOI: https://doi.org/10.11144/Javeriana.cvu1122.pdlc
HE, F.; HU, X. Hubbell's fundamental biodiversity parameter and the Simpson diversity index. Ecology Letters, v. 8, n. 4, p. 386-390, 2005. DOI: https://doi.org/10.1111/j.1461-0248.2005.00729.x

IBGE - INSTITUTO BRASILEIRO DE GEOGRAFIA E ESTATÍSTICA. Censo 2010. Disponível em: http://www.ibge.gov.br/. Acesso em: 08 de nov. 2019. IBGE - Instituto Brasileiro de Geografia e Estatística.

IMAP - INSTITUTO DE MEIO AMBIENTE E ORDENAMENTO TERRITORIAL DO AMAPÁ. Histórico de Loteamentos Urbanos. s.d. Disponível em:

$<$ http:/ /www.imap.ap.gov.br/lista.php?cont $=233 \& a=$ 220> Acesso em: 05 abr. 2020.

KRAMER, J. A.; KRUPEK, R. A. Caracterização florística e ecológica da arborização de praças públicas do município de Guarapuava, PR. Revista Árvore, Viçosa, v. 36, n. 4, p. 647-658, 2012. DOI: http://dx.doi.org/10.1590/s0100-67622012000400007.

LIMA NETO, E. M. Aplicação do Sistema de Informações Geográficas para o inventário da arborização de ruas de Curitiba, PR. 120p. Universidade Federal do Paraná - Dissertação, Curitiba, PR, 2011.

LIMA NETO, E. M.; BIONDI, D. Delineamento de Unidades Amostrais Para o Inventário da Arborização de Ruas em Curitiba, PR. Revista da Sociedade Brasileira de Arborização Urbana, Piracicaba, v. 9, n. 1, p. 21-34, 2014. http://dx.doi.org/10.5380/revsbau.v9i1.66592

LIMA NETO, E. M. Índice e métricas para a gestão das árvores de rua de Boa Vista - $\mathbf{R R}$ a partir de cadastro espacial. 168f. Pós-Graduação em Engenharia Florestal, Universidade Federal do Paraná, Curitiba, 2014.

LOMBARDO, M. A. Ilhas de calor nas metrópoles: o exemplo da cidade de São Paulo. São Paulo: Hucitec, 1985. 244p.

LINS NETO, N. F.; SOUSA, P. R.; VIANA, A. L.; MARI, M. L.; MEDEIROS, S. H. Avaliação da arborização urbana da Cidade de Manaus por seus residentes. Revista Eletrônica em Gestão, Educação e Tecnologia Ambiental, v. 20, n. 1, p. 162-173, 2016. DOI: http://dx.doi.org/10.5902/2236117018934

LONGLEY, P. A; GOODCHILD, M. F; MAGUIRE, D. J; RHIND, D. W. Sistemas e Ciência da Informação Geográfica. 3 ed. Porto Alegre: Bookman, 2013. 539p.

LOPES, W. G. R.; LIMA, A. J.; VIANA, B. A. S.; RODRIGUES NETO, B. A. S. V.; NOGUEIRA, R. H. N. Reflexões sobre o Plano Diretor como instrumento de gestão em municípios brasileiros. GeoUERJ, Rio de Janeiro, v. 1. p, 145-168. 2017. DOI: 10.12957/geouerj.2017.28340

LIRA, W. S; CÂNDIDO, G. A. Gestão sustentável dos recursos naturais: uma abordagem participativa. Campina Grande: EDUEPB, 2013. DOI: https://doi.org/10.7476/9788578792824

LORENZI, H.; SOUZA, H. M.; TORRES, M. A. V.; BACHER, L. B. Árvores exóticas no Brasil: madeireiras, ornamentais e aromáticas. São Paulo: Nova Odessa, 2003. 368 p.

KRIPPENDORFF, K. Teoria matemática da comunicação. In: LITTLEJOHN, S. W.; FOSS, K. A. (Eds.) Encyclopedia of communication theory. Los Angeles, CA: Sage, 2009. p. 614-618. Disponível em: https://repository.upenn.edu/asc_papers/169/ 
MARANHO, A. S.; PAULA, S. R. P. Diversidade em uma área verde urbana: avaliação qualitativa da arborização do campus da Universidade Federal do Acre, Brasil. Agro Ambiente, v. 8, n. 3, p. 404-415, 2014. DOI: http://dx.doi.org/10.18227/19828470ragro.v8i3.1868

MARINHO, A. A.; BRITO, M. R.; MESQUITA, R. A. S.; SANTOS, A. B. A dos. Percepção ambiental dos usuários da Avenida JK - Palmas - Tocantins sobre sua arborização. 2012. 11p. Disponível em: http://ge.catolica-

to.edu.br/portal/portal/downloads/docs_gestaoambien tal/projetos2010-2/4-

periodo/Percepcao_ambiental_dos_usuarios_da_avenid a_jk_palmas_tocantins_sobre_sua_arborizacao.pdf. Acesso: 09 abr. 2020.

MARTINS, L. F. V.; ANDRADE, H. H. B.; ANGELIS, B. L. D. Relação entre odas e aspectos fitossanitários em árvores urbanas na cidade de Luiziana, Paraná. Revista da Sociedade Brasileira de Arborização Urbana, Piracicaba, v. 5, n. 4, p. 141-155, 2010. DOI: http://dx.doi.org/10.5380/revsbau.v5i4.66324

MEIRA, G. R. N.; TEIXEIRA, G. G. M.; VENTURIN, P. R. F.; GOTTSTEIN, P.; CAXAMBU, M. G. Avaliação quali-quantitativa de espécies arbóreas no perímetro urbano da cidade de Corumbataí do Sul - PR. Revista da Sociedade Brasileira de Arborização Urbana, Piracicaba, v. 10, n. 4, p. 36-49, 2015. DOI: http:/ /dx.doi.org/10.5380/revsbau.v10i4.63383

MELO, A. S. O que ganhamos 'confundindo' riqueza de espécies e equabilidade em um índice de diversidade? Biota Neotropica, v. 8, n. 3, p. 21-27, 2008. DOI: https://doi.org/10.1590/S1676-06032008000300001

MELO, E. F. R. Q.; ROMANINI, A. Praça Ernesto Tochetto: Importância da sua Preservação Histórica e Aspectos de sua Arborização. Revista da Sociedade Brasileira de Arborização Urbana, v. 3, n. 1, p. 54-72, 2008. http://dx.doi.org/10.5380/revsbau.v3i1.66251

MILANO, M. S.; DALCIN, E. Arborização de vias públicas. Rio de Janeiro: Light, 2000. 206p.

MOBOT. Missouri Botanical Garden. Tropicos. Disponível em: http://www.tropicos.org/ Acesso em: 26 março 2020.

MOTA, C. M.; MOURÃO, A. E. B.; ALVES, M. M. A.; MOTA, H. R.; CAVAlCANTE, A. C. R. Parâmetros fitossociológicos do estrato arbóreo de áreas de Caatinga em sistema agrossilvipastoril. Fortaleza: Embrapa caprinos e ovinos, 2013. p. 1-5. Disponível em: http://ainfo.cnptia.embrapa.br/digital/bitstream/item/ 94923/1/aac-Parametros-fitossociologicos-do-estratoarboreo-de-areas.pdf

NASCIMENTO, M. S.; RODRIGUES, E. R.; SOUZA, C. A. S.; FARIA, M. J. B.; PEDERASSI, J.; LIMA, M. S. C. S. Análise quali-quantitativa da 78 arborização das áreas públicas do bairro Centro de Resende, RJ. Revista da Sociedade Brasileira de Arborização Urbana, Piracicaba, SP, v. 99, n. 4, p. 113-131, 2014. DOI: http:/ /dx.doi.org/10.5380/revsbau.v9i4.63314

PEREIRA, L. C.; BALBINO, M. V.; FARIAS, N. S. N.; VIANA, L. S.; XAVIER, M. R. R.; CORREA, D. L.; SILVA, T. M. L. Mapeamento e quantificação da cobertura vegetal em áreas periféricas na cidade de Paragominas - PA. Revista da Sociedade Brasileira de Arborização Urbana, v. 14, n. 1, p. 14-28, 2019. DOI: http://dx.doi.org/10.5380/revsbau.v14i1.65254

PIVETTA, K. F.; SILVA FILHO, D. F. Boletim Acadêmico: Série Arborização Urbana. v.1, p. 2. Jaboticabal: UNESP/FCAV, ESALQ/USP, 2002. 74p. Disponível

em: https://edisciplinas.usp.br/pluginfile.php/90233/mod_ resource/content/1/arborizaourbana-unespjaboticabal111215112201-phpapp01.pdf

PORTILHO, I. dos S. Políticas de desenvolvimento urbano em espaços segregados: uma análise do PDSA na cidade de Macapá (AP). Dissertação (Mestrado) Pós-Graduação em Geografia. 166f. Universidade Federal do Pará. Belém: UFPA, 2006.

REDIN, C. G.; VOGEL, C.; TROJAHN, C. D. P.; GRACIOLI, C. R.; LONGHI, S. J. Análise da Arborização Urbana em cinco praças do município de Cachoeira do Sul, RS. Revista da Sociedade Brasileira de Arborização Urbana, v. 5, n. 3, p. 149-164, 2010. DOI: http://dx.doi.org/10.5380/revsbau.v5i3.66310

RIBEIRO, F. A. B. S. Arborização urbana em Uberlândia: percepção da população. Revista da Católica, Uberlândia, v. 1, n. 1, p. 224-237, 2009.

RODOLFO JÚNIOR, F.; MELO, R. R.; CUNHA, T. A.; STANGERLIN, D. M. Análise da Arborização Urbana em bairros da cidade de Pombal no Estado da Paraíba. Revista da Sociedade Brasileira de Arborização Urbana, Piracicaba, v. 3, n. 4, p. 3-19, 2008. DOI: http://dx.doi.org/10.5380/revsbau.v3i4.66369

RODRIGUES, T. D.; MALAFAIA, G.; QUEIROZ, S. E. E.; RODRIGUES, A. S. L. Percepção sobre arborização de moradores em três áreas de Pires do Rio - Goiás. Revista de estudos ambientais, Blumenau, v. 12, n. 2, p. 47-61, 2010. DOI: http://dx.doi.org/10.7867/19831501.2010v12n2p47-61

ROLLON, M. S.; SIQUEIRA, M. V. B. M. Diagnóstico arbóreo comparativo em bairros de Lençóis Paulista - SP. Revista da Sociedade Brasileira de Arborização Urbana, Piracicaba, v. 13, n. 1, p. 43-56, 2018. DOI: http://dx.doi.org/10.5380/revsbau.v13i1.63598

ROMANI, G. N.; GIMENES, R.; SILVA, M. T.; PIVETTA, K. F. L.; BATISTA, G. S. A. Análise Quali-Quantitativa da Arborização na Praça XV de novembro em Ribeirão Preto - SP, Brasil. Revista Árvore, Viçosa, v. 36, n. 3, p. 479-487, 2012. DOI: https://doi.org/10.1590/S010067622012000300010

ROSSETTI, A. I. N.; PELLEGRINO, P. R. M.; TAVARES, A. R. As Árvores e suas interfaces no ambiente urbano. Revista da Sociedade Brasileira de Arborização Urbana, Piracicaba, v. 5, n. 1, p. 1-24, 2010. DOI: http://dx.doi.org/10.5380/revsbau.v5i1.66231

SANTOS, A. F.; JOSÉ, A. C.; SOUSA, P. A. de. Fitossociologia e diversidade de espécies arbóreas das praças centrais do município de Gurupi -TO. Revista da Sociedade Brasileira de Arborização Urbana, Piracicaba, v. 8, n. 4, p. 36-46, 2013. DOI: http://dx.doi.org/10.5380/revsbau.v8i4.66511

SANTOS, M. O.; MAIA, L. P. S. S.; OLIVEIRA, E. D.; SILVA NETO, J. C. A.; CELLA, W. Percepção ambiental sobre a arborização urbana no 4587111172. Revista Ra'e Ga: o espaço geográfico em análise, Curitiba, v. 44, p. 231-241, 2018. DOI: http://dx.doi.org/10.5380/raega.v44i0.49540

SANTOS, V. K. Uma generalização da distribuição do índice de diversidade generalizado por Good com 
aplicação em ciências agrárias. 2009. 57 f. Dissertação (Mestrado em Biometria e Estatística Aplicada) - Curso de Pós-graduação em Biometria e Estatística Aplicada, Universidade Federal Rural de Pernambuco, Recife, 2009.

SHAMS, J. C. A.; GIACOMELI, D. C.; SUCOMINE, N. M. Emprego da arborização na melhoria do conforto térmico nos espaços livres públicos. Revista da Sociedade Brasileira de Arborização Urbana, Piracicaba, v. 4, n. 4, p. 1-16, 2009. DOI: http://dx.doi.org/10.5380/revsbau.v4i4.66445

SILVA, F. F.; FIDELIS, M. E. A.; CASTRO, P. F. Arborização e acessibilidade em calçada: Comentários sobre o deslocamento entre campi da Universidade Federal Fluminense. Revista da Sociedade Brasileira de Arborização Urbana, Piracicaba, v. 6, n. 3, p. 43-63, 2011. http://dx.doi.org/10.5380/revsbau.v6i3.66473

SUFIA, M. C. S.; SOUZA, G. S.; SIQUEIRA, M. V. B. M. Percepção ambiental sobre arborização urbana em regiões distintas do município de Bauru - SP. Revista da Sociedade Brasileira de Arborização Urbana, Curitiba, v. 13, n. 4, p. 15-28, 2019. DOI: http://dx.doi.org/10.5380/revsbau.v13i4.65135

URAMOTO, K.; WALDER, J. M. M.; ZUCCHI, R. A. Análise quantitativa e distribuição de populações de espécies de Anastrepha (Diptera: Tephritidae) no campus Luiz de Queiroz, Piracicaba, SP. Neotropical Entomology, Londrina, v. 34, n. 1, p. 33-39, 2005. DOI: https://doi.org/10.1590/S1519-566X2005000100005.

TEIXEIRA, I. F.; SANTOS, N. R. Z.; BALEST, S. S. Percepção ambiental dos moradores de três loteamentos particulares em Santa Maria (RS) quanto a arborização de vias públicas. Revista da Sociedade Brasileira de Arborização Urbana, Piracicaba, v. 4, n. 1, p. 58-78, 2009. http://dx.doi.org/10.5380/revsbau.v4i1.66271

THE PLANT LIST. Royal Botanic Gardens, Kew and Missouri Botanical Garden. Disponível em: < http://www.theplantlist.org/>. Acesso em: 12/03/2020.

VELOSO, J. N. Inventário da arborização urbana das principais avenidas do Município de Rorainópolis, Roraima. Boletim do Museu Integrado de Roraima, Boa Vista, v. 10, n. 2, p. 28-40, 2016. DOI: https://doi.org/10.24979/bolmirr.v10i02.787 